\title{
Prognostic Significance of Programmed Cell Death Ligand 1 (PD-L1), CD8+ Tumor-Infiltrating Lymphocytes and p53 in Non-Small Cell Lung Cancer: An Immunohistochemical Study
}

\author{
Hayam E. RASHED', Aziza E. ABDELRAHMAN', Mohamed ABDELGAWAD², Safa BALATA², \\ Mohamed EI SHABRAWY3
}

Department of ${ }^{1}$ Pathology, ${ }^{2}$ Clinical Oncology and Nuclear Medicine, and ${ }^{3}$ Chest, Zagazig University, Faculty of Medicine, ZAGAZIG, EGYPT

\begin{abstract}
Objective: Programmed cell death ligand-1 interacts with the immune receptors on the surface of CD8+ tumor infiltrating lymphocytes and PD-1, thereby blocking its anti-tumor activity. Therapeutics suppression of this interaction will show a promise in the treatment of non-small cell lung cancer by restoring the functional anti-tumor T-cell activity. We aimed to evaluate the association between the immunohistochemical expression of PD-L1, stromal CD8+ tumor infiltrating lymphocytes and p53 with the clinicopathological characteristics, response to chemotherapy, progression-free-survival, and overall survival.

Material and Method: We examined the immunohistochemical expression of PD-L1, stromal CD8+ TILs, and p53 expression in 50 patients with advanced stage (III\&IV) non-small cell lung cancer.

Results: PD-L1 was expressed in 56\% of the studied cases. PD-L1 expression was related to unfavorable response to the therapy without significant difference. PD-L1 expression was significantly associated with disease progression, poor progression-free-survival \& overall survival. CD8+ TILs were high in $32 \%$ of the cases. Tumors with high CD8+ TILs showed a partial response to therapy and had a better progression-free-survival and overall survival. p53 expressed in $82 \%$ of the studied cases. There was a significant negative association between PD-L1 and CD8+ TILs $(\mathrm{p}=0.009)$, while a non-significant association was found between $\mathrm{p} 53$ and PD-L1 ( $\mathrm{p}=0.183)$.
\end{abstract}

Conclusion: PD-L1 overexpression is an unfavorable prognostic marker, while the high CD8 + TILs is a good prognostic marker in non-small cell lung cancer. PD-L1 immunohistochemical assessment may be used for the selection of patients legible for treatment with anti-PD-L1 therapy.

Key Words: PD-L1, p53, Tumor infiltrating lymphocytes, Non-small cell lung cancer, Immunohistochemistry.

\section{INTRODUCTION}

Lung cancer ranks the first in the incidence and mortality rates amongst all malignancies worldwide. Non-small cell lung cancer (NSCLC) constitutes $80 \%$ - 85\% of all diagnosed cases and more than $70 \%$ of NSCLC are diagnosed as an advanced or late disease (1).

Recognition of tumor antigens by $\mathrm{T}$ cells leads to activation of anti-tumor immune reaction mainly by cytotoxic $\mathrm{CD}+8$ tumor infiltrating lymphocytes (TILs), but malignant cells may have many pathways to evade the immunological destruction. PD-1 is a co-stimulatory molecule on T-cells that inhibits T cell activation. PD-1, which is a 288 -amino acid cell-surface protein, can bind two ligands, PD-L1 and PD-L2, which negatively control the immune response. Tumor cells express PD-L1 can inhibit T cell-mediated immune response and can progress to distant metastasis $(2,3)$.

(Turk Patoloji Derg 2017, 33:211-222)

Received : 12.02.2017 Accepted : 19.03.2017
CD8 marker is expressed on cytotoxic T cells, natural killer, and dendritic cells. CD8+ T cells are a major component of the cell-mediated immune system against malignant cells. CD8 + T cells undergo differentiation to effector cytotoxic T cells. Then the effector CD8+ cells undergo apoptosis leaving memory cells when a pathogenic response is resolved. Memory $\mathrm{T}$ cells and cytotoxic $\mathrm{T}$ cells are associated with a more favorable prognosis in NSCLC (4).

PD-L1 over-expression has been proved to be a poor prognostic marker in many human cancers (5). PD-1/ PD-L1 interaction suppresses CD8+ TILs survival and proliferation and leads to apoptosis of tumor-infiltrating lymphocytes. PD-L1 over-expression in tumor cells in a syngeneic transplant model of tumor cells makes them evade from cytotoxic TILs (6).

Correspondence: Aziza E. ABDELRAHMAN

Department of Pathology, Zagazig University, Faculty of Medicine,

ZAGAZIG, EGYPT

E-mail: azaelsayed@gmail.com Phone: +00 201068743218 
Blockage of PD-1/PD-L1 interaction with monoclonal antibodies will restore T cellactivity in the microenvironment of the tumor and has been stated to result in an effective anti-tumor therapeutic effect in clinical trials and may have promising activity in many malignancies (7).

Inactivation of $\mathrm{p} 53$, which is a tumor suppressor gene present on the short arm of chromosome 17 (17p13), is a constant feature of most of the human malignancies that often characterized by aggressive behavior, poor overall survival, and treatment failure (8).

The standard treatment of advanced NSCLC according to the tumor stage was limited to radiotherapy, chemotherapy or both. Recently, targeted molecular therapies have replaced the traditional therapeutic methods for patients whose cancers express certain genetic alterations. Attempts to provide immunotherapy in lung cancers were accelerated and now the development of therapeutics targeting PD-1 and PD-L1 has developed. An immunotherapy will be stated as the third line in the treatment of advanced lung cancer $(7,9)$.

In this study, we aimed to evaluate the association between the immunohistochemical expression of programmed cell death ligand 1 (PD-L1), stromal CD8+ TILs and p53 with clinicopathological characteristics, response to chemotherapy, progression free-survival (PFS) and overall survival (OS) in patients with NSCLC.

\section{MATERIAL and METHODS}

Patients: This is an analytic cross-sectional study, which was conducted in Clinical oncology, Chest and Pathology Departments, Zagazig University Hospitals, in the period from January 2014 to August 2016. The study was carried out on 50 patients with advanced stage (III\&IV) NSCLC (10).

Patients were subjected to the followings; 1-Thorough medical history 2- Full clinical examination 3- Laboratory investigations, including the following: (a) Complete blood count, (b) Kidney function tests (serum urea level and creatinine), (c) Liver function tests, and (d) PT, PTT \& INR. 4- Plain chest X-ray: the postero-anterior view was done to all patients by X-ray machine (ROTALiX SRT 32, Philips, Italy), the chest radiographs showed pulmonary nodule, mass, infiltrate, mediastinal widening, atelectasis, hilar enlargement or presented by pleural effusion. 5Computed tomography (C.T): conventional chest C.T was done in all cases, where CT-guided transthoracic core tissue biopsy was done for peripherally located lesions. Three-four biopsies are likely adequate in this situation.
6- Bronchoscopy: patients who had radiologically central lesion were subjected to FOB (Pentax FB15TV, Philips, Tokyo, Japan). Flexible bronchoscopy was performed with a fiberoptic scope through transnasal route under topical anesthesia (2\% lignocaine). Oxygenation was monitored throughout the procedure with pulse oximetry (11).

Patients received platinum-based doublet chemotherapy (carboplatin and gemcitabine). The clinical response to chemotherapy was evaluated using computed tomography (CT). Clinical follow-up data were taken in all cases. Patient follow-up information was obtained from hospital records or patient contact. The study complied with the guidelines of institutional review board of Zagazig university hospitals.

Immunohistochemical Staining: All tissues were fixed at $10 \%$ neutral formaldehyde solution. Then, dehydration and paraffin embedding were done, followed by deparaffinization in xylene and rehydration in descending series of alcohols. For antigen retrieval, $10 \mathrm{mM}$ citrate buffer ( $\mathrm{pH}$ 6.0) at the microwave for 20 minutes was used. Endogenous peroxidise activity was blocked by $3 \%$ hydrogen peroxide for $10 \mathrm{~min}$. After repeat washing in PBS, the slides were incubated with primary mouse monoclonal antibodies directed against anti-PD-L1 (sc293425, Santa Cruz Biotechnology, Santa Cruz, CA) and mouse anti-human p53 (DO-7, Dako, 1:100) and Anti-CD8 (clone C8/144B, Dako, ready to use). Binding site of primary antibodies was visualized by using the Dako EnVision ${ }^{\mathrm{T}}$ kit (Dako, Copenhagen, Denmark). Then, the sections were counterstained with Mayer's hematoxylin. Negative controls were obtained by omission of the primary antibody. The tonsils, placenta and colon cancer tissues were used as positive control for CD8+ TILs, PD-L1 and p53 respectively.

Immunohistochemistry: PD-L1 was assessed as negative, weak positive which was defined as a membranous or cytoplasmic PD-L1 expression in 1\% to $49 \%$ of tumor cells, and PD-L1 strong positive was defined as expression in $\geq 50 \%$ of tumor cells at higher power magnification. In this work, negative and weak positive stain was considered as a negative group (11). p53 nuclear stain in more than $5 \%$ of malignant cells was considered a positive immunoreactivity and its expression was evaluated as follow: p53-negative ( $\leq$ $5 \%)$, low p53 (5\% to 50\%), and high p53 (> 50\%) (12). The percentages of CD8+ TILs compared with the total amount of nucleated cells in the stroma were evaluated; low density: $\leq 25 \%$; intermediate density: $\geq 25 \%$ to $\leq 50 \%$; high density: $>50 \%$ (13).

Statistical Analysis: Continuous variables were expressed as the mean \pm SD \& median (range), and the categorical 
variables were expressed as a number (percentage). Continuous variables were checked for normality by using the Shapiro-Wilk test. Independent samples Student's t-test was used to compare between two groups of normally distributed variables. One Way ANOVA test was used to compare between more than two groups of normally distributed variables, while Kruskal-Wallis $\mathrm{H}$ test was used for non-normally distributed variables. Percent of categorical variables were compared using Pearson's Chisquare test or Fisher's exact test when was appropriate. The trend of change in the distribution of relative frequencies of ordinal data was compared using the chi - square test for trend. PFS was calculated as the time from the assessment of response to treatment (baseline) to progression or the most recent follow-up in which no progression. Overall Survival (OS) was calculated as the time from diagnosis to death or the most recent follow-up contact (censored). Stratification of PFS and OS was done according to the immunohistochemical markers. These time-to-event distributions were estimated using the method of KaplanMeier plot and compared using two-sided exact logrank test. A p-value $<0.05$ was considered significant. All statistics were performed using SPSS 22.0 for Windows (SPSS Inc., Chicago, IL, USA) and MedCalc windows (MedCalc Software bvba 13, Ostend, Belgium).

\section{RESULTS}

Patients and the Clinicopathological Parameters: Our study included 50 patients; $82 \%$ of them were males, with an age ranged from 25 to 77 years (mean: $55.56 \pm 14.18$ ). Thirty cases (60\%) were diagnosed as adenocarcinoma and $20(40 \%)$ cases as squamous cell carcinomas. Nineteen cases were moderately differentiated (grade II) and 31 were poorly differentiated (grade III). Tumors were classified as stage III $(n=29)$, and stage IV $(n=21)$. Half of the patients gave a partial response and 24 patients survive more than 9 months (Table I).

Table I: Clinicopathological parameters, immunohistochemical markers and outcome of 50 patients with NSCLC

\begin{tabular}{|c|c|c|c|c|c|}
\hline Characteristics & Number & $\%$ & Characteristics & Number & $\%$ \\
\hline Age (year) & & & CD8+ TILs & & \\
\hline Mean \pm SD & $55.56 \pm 14.18$ & & Low & 28 & $56 \%$ \\
\hline Median (Range) & $55(25-77)$ & & Intermediate & 6 & $12 \%$ \\
\hline$<65$ years & 35 & $70 \%$ & High & 16 & $32 \%$ \\
\hline$\geq 65$ years & 15 & $30 \%$ & Response & & \\
\hline Sex & & & $\mathrm{PD}$ & 10 & $20 \%$ \\
\hline Male & 41 & $82 \%$ & SD & 15 & $30 \%$ \\
\hline Female & 9 & $18 \%$ & $\mathrm{PR}$ & 25 & $50 \%$ \\
\hline Pathology & & & NR & 25 & $50 \%$ \\
\hline SCC & 20 & $40 \%$ & OAR & 25 & $50 \%$ \\
\hline Adenocarcinoma & 30 & $60 \%$ & Follow-up (months) & & \\
\hline Grade & & & Mean \pm SD & $10.60 \pm 4.58$ & \\
\hline Grade II & 19 & $38 \%$ & Median (Range) & $10(5-19)$ & \\
\hline Grade III & 31 & $62 \%$ & Progression & & \\
\hline Stage & & & Within 6 months & 22 & $55 \%$ \\
\hline Stage III & 29 & $58 \%$ & After 6 months & 18 & $45 \%$ \\
\hline Stage IV & 21 & $42 \%$ & Survival & & \\
\hline PD-L1 & & & $<9$ months & 26 & $52 \%$ \\
\hline Negative & 22 & $44 \%$ & $>9$ months & 24 & $48 \%$ \\
\hline Positive & 28 & $56 \%$ & & & \\
\hline \multicolumn{6}{|l|}{ p53 } \\
\hline Negative & 8 & $16 \%$ & & & \\
\hline Low & 17 & $34 \%$ & & & \\
\hline High & 25 & $50 \%$ & & & \\
\hline
\end{tabular}

Continuous variables were expressed as mean \pm SD \& median (range); categorical variables were expressed as number (percentage). PD means progressive disease, SD: stable disease, PR: partial response, NR: no response, OAR: overall response. 
Association Between PD-L1 Expression and the Clinicopathological Parameters: PD-L1 immunoreactivity was detected as membranous and/or cytoplasmic stain in the malignant cells in 56\% of NSCLC cases, but the adjacent paratumor tissues didn't express. (Figure 1A, B). Regarding histopathology, PD-L1 was overexpressed in adenocarcinoma variant ( $60 \%$ of cases) more than squamous cell carcinoma (50\% of cases). There was a significant difference between PD-L1 expression as regards the stage $(p<0.001)$ but not with the age, sex, pathological type and tumor grade. There was a negative correlation between PDL1 immunoreactivity and CD8+ TILs $(p=0.009)$ (Table II).

Association Between p53 Expression and the Clinicopathological Parameters: p53 immunoreactivity was detected as a nuclear stain (Figure 2A,B). The percentage of p53 positive cases in NSCLC was $82 \%$. p53 was overexpressed in adenocarcinoma (93.3\% of cases) more than squamous cell carcinoma (70\% of cases) $(p=0.05)$. There was a non-significant difference between p53 expression in NSCLC as regards age, sex, pathological type, tumor grade and stage. No significant association was found between p53 and PD-L1 expression in NSCLC $(p=0.183)$ (Table II).

Association Between CD8+ TILs Expression and the Clinicopathological Parameters: High tumor-infiltrating CD8+ TILs was observed in the stroma of $32 \%$ of the cases, while intermediate CD8+TILs density was found in $12 \%$ of the cases (Figure 3A, B). There was a significant difference between CD8+ TILs expression as regards tumor stage $(p<0.001)$ but no difference with the age, sex, pathological type and tumor grade was observed (Table III).
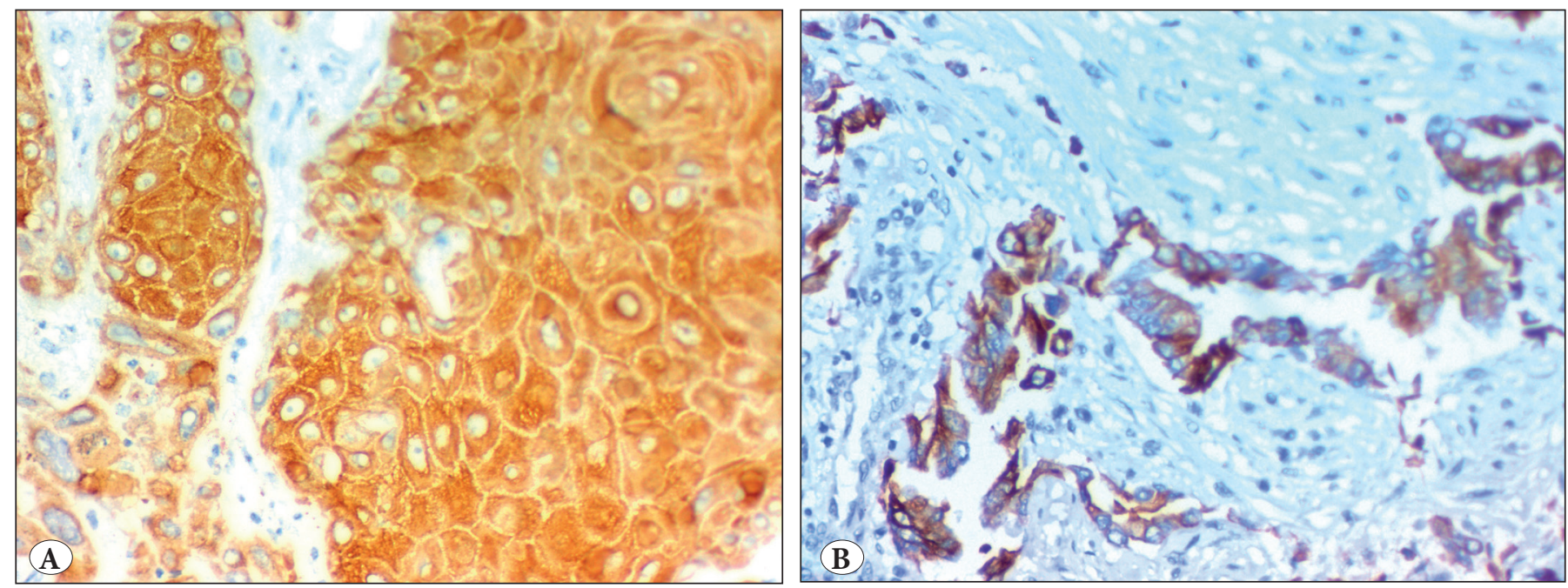

Figure 1: Representative immunohistochemical staining results for PD-L1. A) PD-L1 positive cytoplasmic stain in lung squamous cell carcinoma (PD-L1; x400). B) PD-L1 positive membranous and cytoplasmic stain in lung adenocarcinoma (PD-L1; x400).
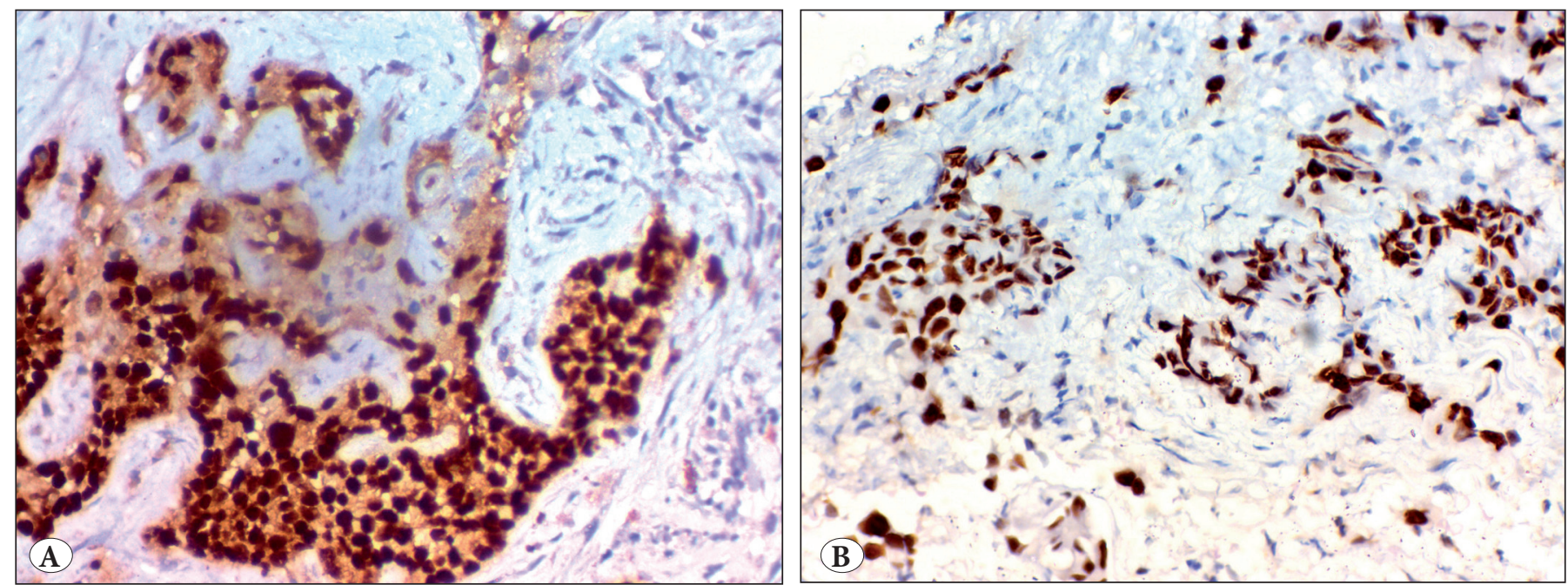

Figure 2: Representative immunohistochemical staining results for p53: A) High nuclear p53 expression in lung squamous cell carcinoma (p53; x400). B) High nuclear p53 expression in lung adenocarcinoma (p53; x400). 
Association Between PD-L1, p53 and CD8+TILs Expression and Patient Outcome: PD-L1 expressing NSCLC was significantly associated with disease progression $(p=0.001)$. In addition, Progressive disease expressed high p53 more than stable disease $(p=0.014)$. PDL1-positive NSCLC were related to unfavorable response to therapy, but without significant difference $(p=0.269)$ (Table IV). Patients with high CD8+ TILs gave a partial response to therapy $(p=0.022)($ Table $\mathrm{V})$.

Kaplan-Meier survival curve analysis revealed a significant association between PD-L1 with shorter PFS and poor OS ( $p=0.001, p=0.011$ respectively), while CD8+ TILs had a better PFS and OS ( $p=0.001$ for each). However, no significant relationship was found between p53 and PFS or OS $(p=0.470, p=0.186)$ (Figure $4 \mathrm{~A}-\mathrm{C}, 5 \mathrm{~A}-\mathrm{C})$.
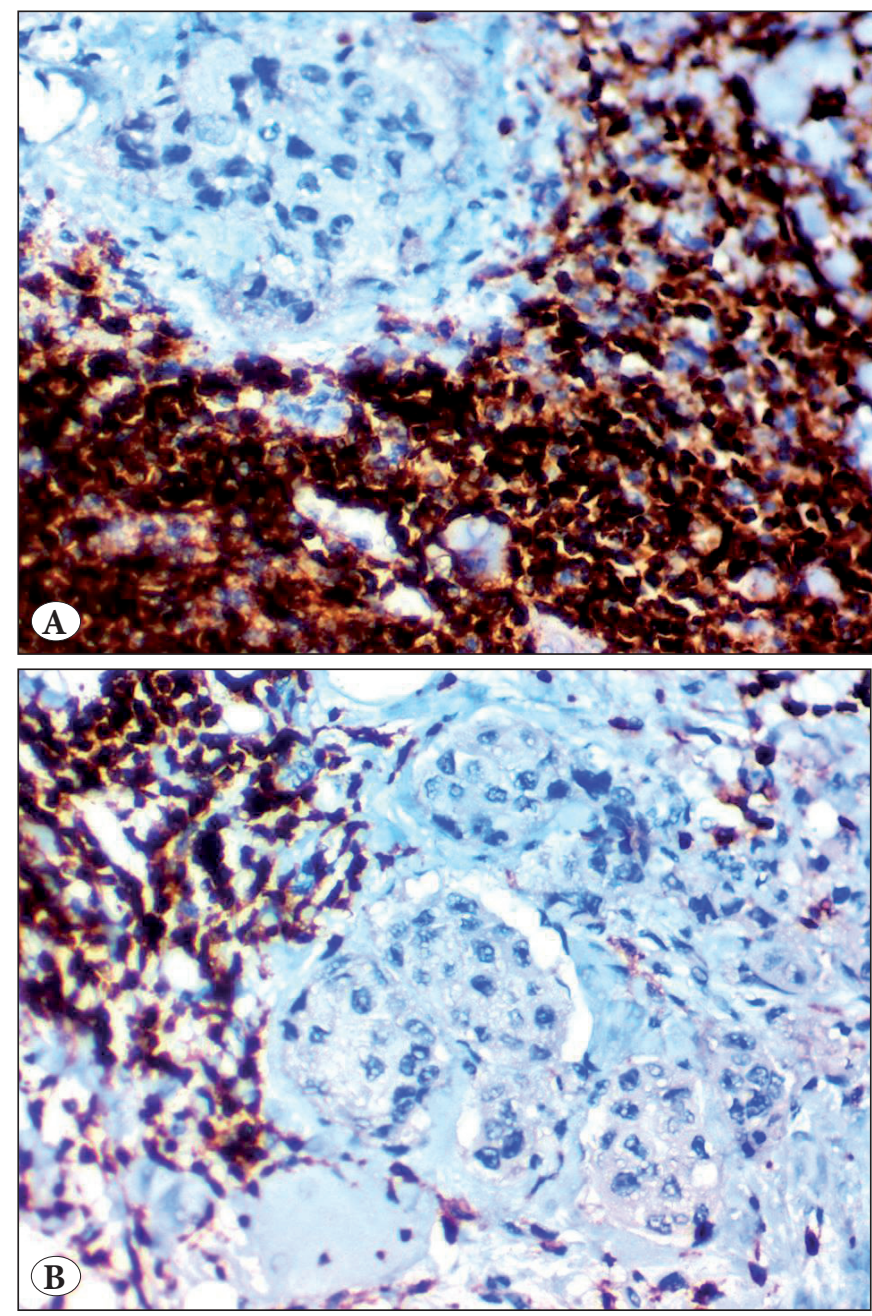

Figure 3: Representative immunohistochemical staining results for CD8+TILs. A) High density of CD8+ TILs in lung squamous cell carcinoma (CD8; x400). B) Intermediate density of CD8+ TILs in lung squamous cell carcinoma (CD8; x400). TILs: Tumor infiltrating lymphocytes
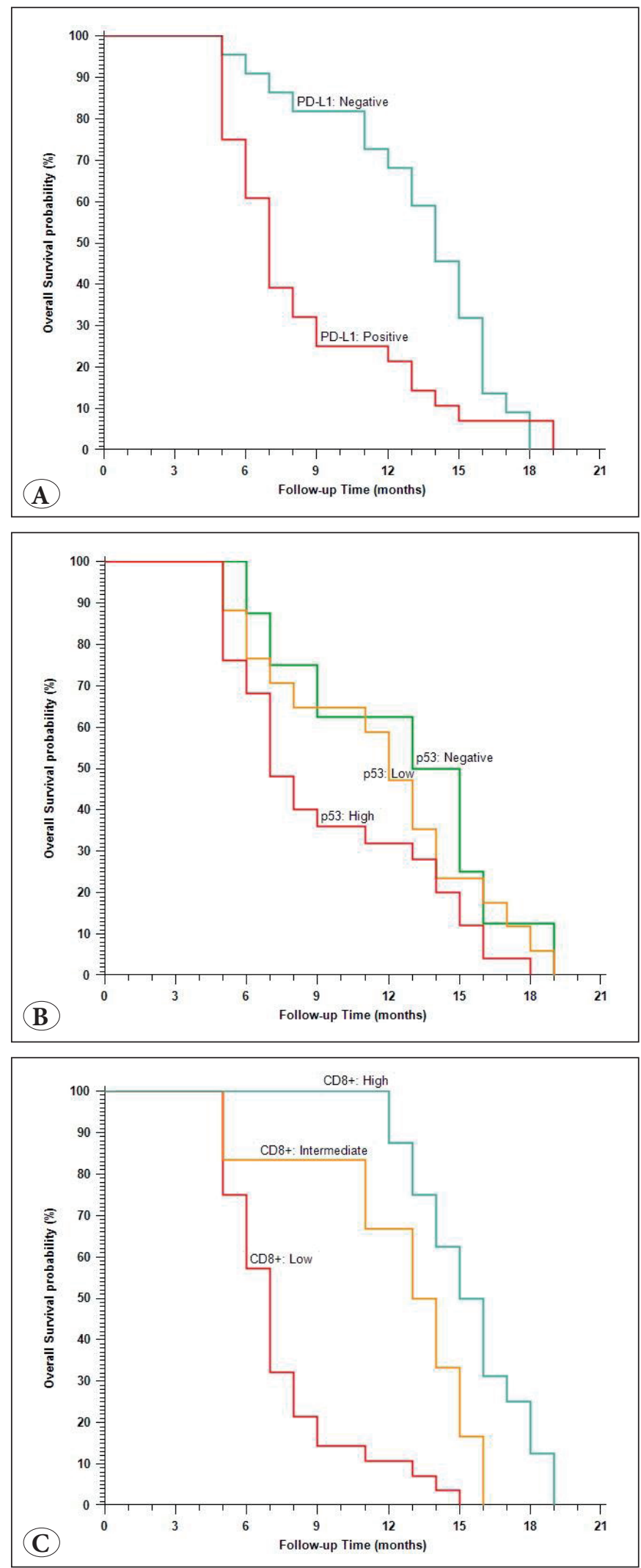

Figure 4: Kaplan-Meier Plot of overall survival: A) Stratified by PD-L1 IHC staining. B) Stratified by p53 IHC staining. C) Stratified by CD8+ TILs IHC staining. (IHC: Immunohistochemical) 


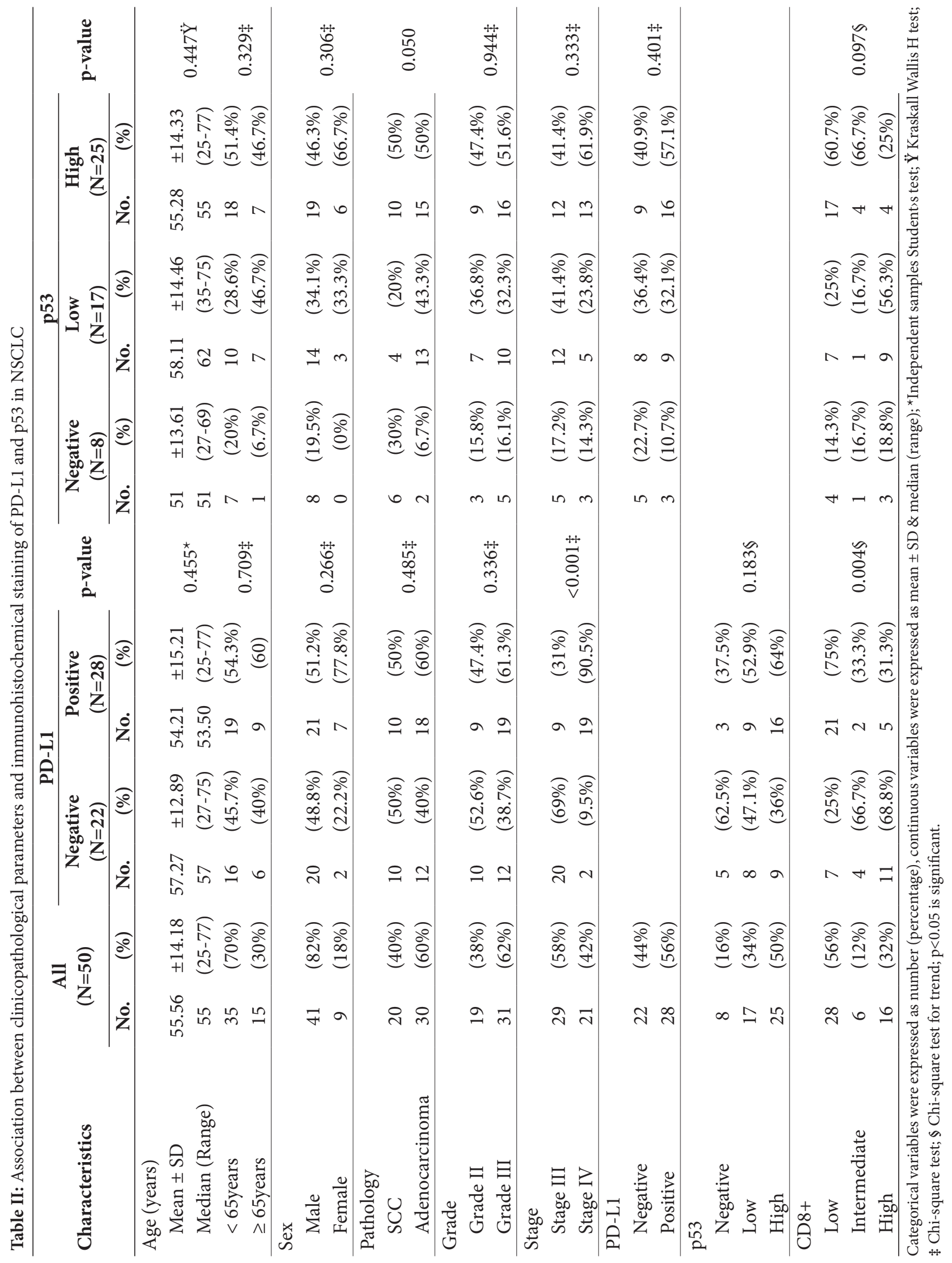




\section{DISCUSSION}

Five-year overall survival rate of NSCLC is $15 \%$ of all stages (1) and less than 5\% for metastatic NSCLC (14), so there is an urgent need to develop other therapeutic modalities to improve outcome of NSCLC especially late stages. Programmed cell death-ligand 1 (PD-L1) is a costimulatory molecule B7 family expressed on the surface of antigenpresenting cells and acts as a negative immune regulatory molecule. It inhibits $\mathrm{T}$ cell activity, increases $\mathrm{T}$-cells apoptosis, decreases tumor immunity and lastly leads to tumor immune escape (15).

Immunotherapy has promising results to improve the outcome of several solid tumors. Therapies targeting the programmed cell death receptor PD-1 and its ligand PD-L1 have revealed promising effects. However, in lung cancer,
PD-L1 diagnostic, prognostic and predictive values remain to need more studies. Previous studies (16-19) showed that NSCLC over-expressed PD-L1 has ranged from 19\% to $100 \%$. However, in this study, the percentage of PDL1positive cases in NSCLC was $56 \%$ and the expression increased with the more advanced stage. In addition, PDL1 reaction was more with adenocarcinoma histology variant, but without a statistically significant difference. On the other hand, one study stated that the PD-L1 expression was associated with adenocarcinoma (17) and the other reported it to be associated with squamous cell carcinoma variant (20). This difference and the wide range of immunohistochemical expression may be related to different antibodies used, genetic, environmental factors and sample size.

Table III: Association between clinicopathological parameters and immunohistochemical staining for CD8+ TILs in NSCLC.

\begin{tabular}{|c|c|c|c|c|c|c|c|c|c|}
\hline \multirow{3}{*}{ Characteristics } & \multirow{2}{*}{\multicolumn{2}{|c|}{$\begin{array}{c}\text { All } \\
(\mathrm{N}=50)\end{array}$}} & \multicolumn{6}{|c|}{ CD8+TILs } & \multirow{3}{*}{ p-value } \\
\hline & & & \multicolumn{2}{|c|}{$\begin{array}{c}\text { Low } \\
(\mathrm{N}=28)\end{array}$} & \multicolumn{2}{|c|}{$\begin{array}{c}\text { Intermediate } \\
(\mathrm{N}=6)\end{array}$} & \multicolumn{2}{|c|}{$\begin{array}{c}\text { High } \\
(\mathrm{N}=16)\end{array}$} & \\
\hline & No. & $(\%)$ & No. & $(\%)$ & No. & $(\%)$ & No. & $(\%)$ & \\
\hline \multicolumn{10}{|l|}{ Age (years) } \\
\hline Mean \pm SD & 55.56 & \pm 14.18 & 55.67 & \pm 15.05 & 61.50 & \pm 8.43 & 53.12 & \pm 14.30 & \multirow{2}{*}{$0.475^{\star}$} \\
\hline Median (Range) & 55 & $(25-77)$ & 56 & $(25-77)$ & 63 & $(51-74)$ & 54 & $(27-75)$ & \\
\hline$<65$ years & 35 & $(70 \%)$ & 18 & $(51.4 \%)$ & 5 & $(14.3 \%)$ & 12 & $(34.3 \%)$ & \multirow{2}{*}{$0.567 \ddagger$} \\
\hline$\geq 65$ years & 15 & $(30 \%)$ & 10 & $(66.7 \%)$ & 1 & $(6.7 \%)$ & 4 & $(26.7 \%)$ & \\
\hline \multicolumn{10}{|l|}{ Sex } \\
\hline Male & 41 & $(82 \%)$ & 21 & $(51.2 \%)$ & 5 & $(12.2 \%)$ & 15 & $(36.6 \%)$ & \multirow{2}{*}{$0.296 \neq$} \\
\hline Female & 9 & $(18 \%)$ & 7 & $(77.8 \%)$ & 1 & $(11.1 \%)$ & 1 & $(11.1 \%)$ & \\
\hline \multicolumn{10}{|l|}{ Pathology } \\
\hline SCC & 20 & $(40 \%)$ & 8 & $(40 \%)$ & 3 & $(15 \%)$ & 9 & $(45 \%)$ & \multirow{2}{*}{$0.171 \neq$} \\
\hline Adenocarcinoma & 30 & $(60 \%)$ & 20 & $(66.7 \%)$ & 3 & $(10 \%)$ & 7 & $(23.3 \%)$ & \\
\hline \multicolumn{10}{|l|}{ Grade } \\
\hline Grade II & 19 & $(38 \%)$ & 9 & $(47.4 \%)$ & 3 & $(15.8 \%)$ & 7 & $(36.8 \%)$ & \multirow{2}{*}{$0.607 \ddagger$} \\
\hline Grade III & 31 & $(62 \%)$ & 19 & $(61.3 \%)$ & 3 & $(9.7 \%)$ & 9 & $(29 \%)$ & \\
\hline \multicolumn{10}{|l|}{ Stage } \\
\hline Stage III & 29 & $(58 \%)$ & 8 & $(27.6 \%)$ & 5 & $(17.2 \%)$ & 16 & $(55.2 \%)$ & \multirow{2}{*}{$<0.001$} \\
\hline Stage IV & 21 & $(42 \%)$ & 20 & $(95.2 \%)$ & 1 & $(4.8 \%)$ & 0 & $(0 \%)$ & \\
\hline \multicolumn{10}{|l|}{ PD-L1 } \\
\hline Negative & 22 & $(44 \%)$ & 7 & $(31.8 \%)$ & 4 & $(18.2 \%)$ & 11 & $(50 \%)$ & \multirow{2}{*}{$0.009 \ddagger$} \\
\hline Positive & 28 & $(56 \%)$ & 21 & $(75 \%)$ & 2 & $(7.1 \%)$ & 5 & $(17.9 \%)$ & \\
\hline \multicolumn{10}{|l|}{ p53 } \\
\hline Negative & 8 & $(16 \%)$ & 4 & $(50 \%)$ & 1 & $(12.5 \%)$ & 3 & $(37.5 \%)$ & \multirow{3}{*}{$0.097 \S$} \\
\hline Low & 17 & $(34 \%)$ & 7 & $(41.2 \%)$ & 1 & $(5.9 \%)$ & 9 & $(52.9 \%)$ & \\
\hline High & 25 & $(50 \%)$ & 17 & $(68 \%)$ & 4 & $(16 \%)$ & 4 & $(16 \%)$ & \\
\hline
\end{tabular}

Categorical variables were expressed as number (percentage), continuous variables were expressed as mean \pm SD \& median (range); ${ }^{\star}$ One way ANOVA test; $\$$ Chi-square test; $₫$ Chi-square test for trend; $\mathrm{p}<0.05$ is significant. 
In this work, PD-L1 positive NSCLC were significantly related to a poor outcome and more progressive disease. In contrast, no correlation was found between PD-L1 tumor expression and other clinicopathological parameters except tumor stage. So, we stated that PD-L1 plays a role in disease progression and detecting PD-L1 immunoreactivity on NSCLC tissues may evaluate patient's outcome. Previous studies revealed controversy in the prognostic value of PDL1 for NSCLC. There are some studies suggesting a negative prognostic role $(17,21-23)$, while others did not find any prognostic value $(24,25)$. However, other studies reported improved patient outcomes $(20,26)$. This discrepancy may be due to different PD-L1 immunohistochemistry assays, using variable detection antibodies and different cutoff. Clinical trials investigating the efficacy of concomitant treatment with anti-PD-L1 and chemotherapy may give better significant results. Also, a significant association between an improved overall survival and PDL1 immunoreactivity was observed in breast cancer, colorectal carcinoma and metastatic melanoma (27-29).

Malignant cells expressing PD-L1 will interact with the negative signal generating immune receptor on the surface of CD8+T cells and PD-1, thereby blocking anti-tumor activity. Therapeutics suppression of this interaction will show promise in the treatment of many cancers by restoring functional antitumor T-cell activity (30). Our result also showed a negative correlation between PD-L1 and CD8+ TILs. Thus, PD-L1 may function as a negative regulator of T-cell-mediated antitumor immunity. Consistent with Chen et al. (31) study, in which PD-L1 blockade has been shown to stimulate anti-tumoral T-cell responses against PD-L1-expressing tumor cells.

CD8+ $\mathrm{T}$ cells are considered to be an indication of the host immune response to malignant cells. Increased CD+8 TILs have been associated with a better prognosis in many solid neoplasms, including colorectal, melanoma and triplenegative breast carcinoma (4). This study showed that CD8+ TILs have a significant prognostic effect, as the patients with high CD8+ TILs gave a partial response to therapy and had a better survival more than those with low CD8+ TILs; this goes with Donnem et al. (13) who found that the stromal CD8+ TILs density was a strong independent prognostic factor for PFS and OS.

There is increasing evidence that PD-L1 plays a major role in peripheral tolerance (32). This study addressed a negative correlation between PD-L1 and CD+8 TILs. This consistent with Iwai et al. (6) study which stated that the PD-1/PDL1 interaction suppresses CD8+ TILs as PD-L1 overexpression in tumor cells in a syngeneic transplant model of tumor cells makes them evade from cytotoxic TILs.
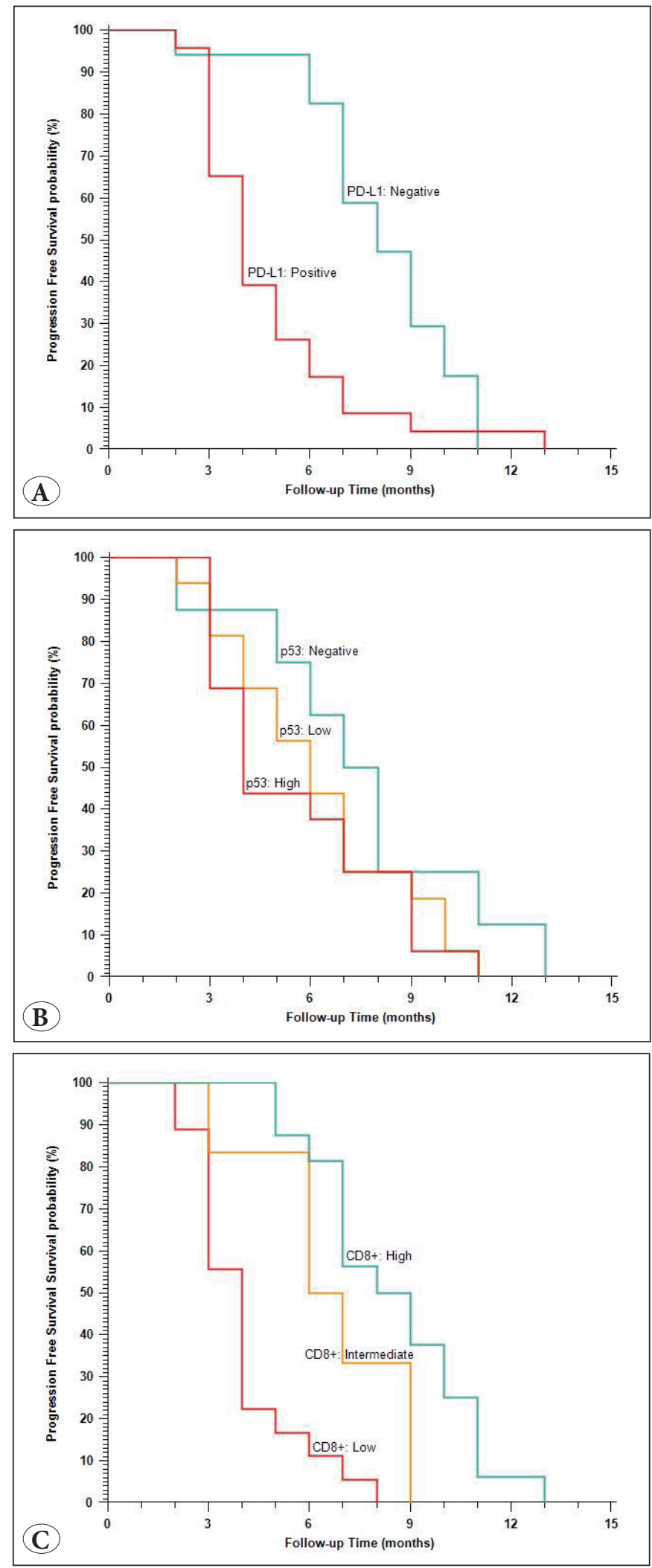

Figure 5: Kaplan-Meier Plot of progression free survival. A) Stratified by PD-L1 IHC staining; B) Stratified by p53 IHC staining; C) Stratified by CD8+ TILs IHC staining. (IHC: Immunohistochemical). 


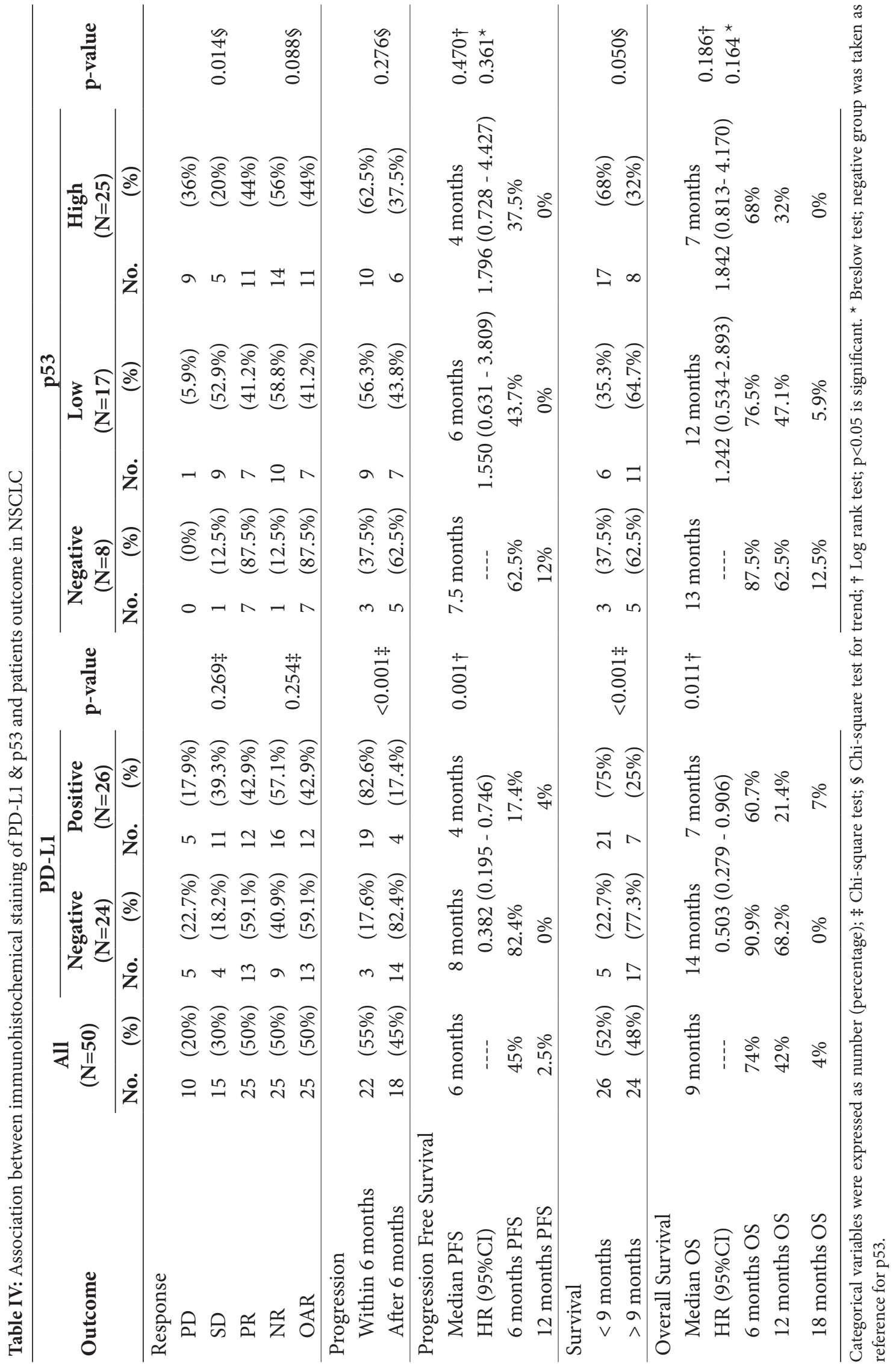


Table V: Association between immunohistochemical staining of CD8+ TILs and patients outcome in NSCLC

\begin{tabular}{|c|c|c|c|c|c|c|c|c|c|}
\hline \multirow{3}{*}{ Outcome } & \multirow{2}{*}{\multicolumn{2}{|c|}{$\begin{array}{c}\text { All } \\
(\mathrm{N}=50)\end{array}$}} & \multicolumn{6}{|c|}{ CD8+TILs } & \multirow{3}{*}{$p$-value } \\
\hline & & & \multicolumn{2}{|c|}{$\begin{array}{c}\text { Low } \\
(\mathrm{N}=28)\end{array}$} & \multicolumn{2}{|c|}{$\begin{array}{c}\text { Intermediate } \\
(\mathrm{N}=6)\end{array}$} & \multicolumn{2}{|c|}{$\begin{array}{l}\text { High } \\
(\mathrm{N}=16)\end{array}$} & \\
\hline & No. & $(\%)$ & No. & $(\%)$ & No. & $(\%)$ & No. & $(\%)$ & \\
\hline \multicolumn{10}{|l|}{ Response } \\
\hline $\mathrm{PD}$ & 10 & $(20 \%)$ & 10 & $(35.7 \%)$ & 0 & $(0 \%)$ & 0 & $(0 \%)$ & \multirow{3}{*}{$0.022 \$$} \\
\hline SD & 15 & $(30 \%)$ & 6 & $(21.4 \%)$ & 3 & $(50 \%)$ & 6 & $(37.5 \%)$ & \\
\hline PR & 25 & $(50 \%)$ & 12 & $(42.9 \%)$ & 3 & $(50 \%)$ & 10 & $(62.5 \%)$ & \\
\hline NR & 25 & $(50 \%)$ & 16 & $(57.1 \%)$ & 3 & $(50 \%)$ & 6 & $(37.5 \%)$ & \multirow{2}{*}{$0.217 \S$} \\
\hline OAR & 25 & $(50 \%)$ & 12 & $(42.9 \%)$ & 3 & $(50 \%)$ & 10 & $(62.5 \%)$ & \\
\hline \multicolumn{10}{|l|}{ Progression } \\
\hline Within 6 months & 22 & $(55 \%)$ & 16 & $(88.9 \%)$ & 3 & $(50 \%)$ & 3 & $(18.8 \%)$ & \multirow{2}{*}{$<0.001 \$$} \\
\hline After 6 months & 18 & $(45 \%)$ & 2 & $(11.1 \%)$ & 3 & $(50 \%)$ & 13 & $(81.3 \%)$ & \\
\hline \multicolumn{10}{|c|}{ Progression Free Survival } \\
\hline Median PFS & \multirow{2}{*}{\multicolumn{2}{|c|}{6 months }} & \multirow{2}{*}{\multicolumn{2}{|c|}{4 months }} & \multirow{2}{*}{\multicolumn{2}{|c|}{$\begin{array}{c}6 \text { months } \\
0.311(0.115-0.840)\end{array}$}} & & onths & \multirow{4}{*}{$\begin{array}{l}<0.001 \dagger \\
<0.001^{\star}\end{array}$} \\
\hline HR (95\%CI) & & & & & & & 0.146 & $61-0.350)$ & \\
\hline 6 months PFS & & $5 \%$ & & $11.1 \%$ & & $\%$ & & $3 \%$ & \\
\hline 12 months PFS & & $5 \%$ & & $0 \%$ & & $\%$ & & $3 \%$ & \\
\hline \multicolumn{10}{|l|}{ Survival } \\
\hline$<9$ months & 26 & $(52 \%)$ & 25 & $(89.3 \%)$ & 1 & $(16.7 \%)$ & 0 & $(0 \%)$ & \multirow{2}{*}{$<0.001 \$$} \\
\hline$>9$ months & 24 & $(48 \%)$ & 3 & $(10.7 \%)$ & 5 & $(83.3 \%)$ & 16 & $(100 \%)$ & \\
\hline \multicolumn{10}{|l|}{ Overall Survival } \\
\hline Median OS & \multirow{2}{*}{\multicolumn{2}{|c|}{9 months }} & \multirow{2}{*}{\multicolumn{2}{|c|}{7 months }} & & onths & \multirow{2}{*}{\multicolumn{2}{|c|}{$\begin{array}{c}15 \text { months } \\
0.122(0.053-0.279)\end{array}$}} & \multirow{5}{*}{$\begin{array}{l}<0.001 \dagger \\
<0.001^{*}\end{array}$} \\
\hline HR (95\%CI) & & & & & 0.288 & $13-0.737)$ & & & \\
\hline 6 months OS & & $4 \%$ & & $57.1 \%$ & & $.3 \%$ & & $0 \%$ & \\
\hline 12 months OS & & $2 \%$ & & $10.7 \%$ & & $.7 \%$ & & $5 \%$ & \\
\hline 18 months OS & & $\%$ & & $0 \%$ & & $\%$ & & $5 \%$ & \\
\hline
\end{tabular}

Categorical variables were expressed as number (percentage); $₫$ Chi-square test for trend; $\dagger$ Log rank test; ${ }^{\star}$ Breslow test; low group was taken as reference for CD+ TILs. $\mathrm{p}<0.05$ is significant.

A p53 gene mutation inhibits the tumor suppressor gene and enables malignant cells to behave more aggressive and spread to different sites. This genetic defect is detected in more than $50 \%$ of the resected NSCLCs (33). However, in this study p53 was over-expressed in $82 \%$ of cases as all our cases were at an advanced stage. To test if PD-L1 correlates with the activation of apoptotic pathways, we analyzed the relationship between it and p53 expression in NSCLC. However the association was non-significant, this was in contrast to Kan and Dong (34), who hypothesized that the PD-L1 expression is significantly related to p53 protein expression in hepatocellular carcinoma.

In conclusion, a large proportion of advanced NSCLC cases have a positive PD-L1 immunoreactivity as reported by previous studies, so they may be potentially responsive to PD-L1 immunotherapy. Immunohistochemical expression of stromal CD8+ TILs had a favorable prognostic impact in NSCLC in contrast to PD-L1 over-expression. Further studies to confirm our observations and to assess the predictive value of anti-PD-L1 immunotherapy in NSCLC are necessary.

\section{CONFLICT of INTEREST}

The authors declare that they have no conflict of interest.

\section{REFERENCES}

1. Siegel R, Naishadham D, Jemal A. Cancer statistics. CA Cancer J Clin. 2013;63:11-30.

2. Topalian SL, Hodi FS, Brahmer JR, Gettinger SN, Smith DC, McDermott DF, Powderly JD, Carvajal RD, Sosman JA, Atkins MB, Leming PD, Spigel DR,Antonia SJ, Horn L, Drake CG, Pardoll DM, Chen L, Sharfman WH, Anders RA, Taube JM, McMiller $\mathrm{TL}, \mathrm{Xu} \mathrm{H}$, Korman AJ, Jure-Kunkel M, Agrawal S,McDonald D, Kollia GD, Gupta A, Wigginton JM, Sznol M. Safety, activity, and immune correlates of anti-pd-1 antibody in cancer. N Engl J Med. 2012;366:2443-54. 
3. Pardoll DM. The blockade of immune checkpoints in cancer immunotherapy. Nat Rev Cancer. 2012;12:252-64.

4. Fridman WH, Pages F, Sautes-Fridman C, Galon J. The immune contexture in human tumours: Impact on clinical outcome. Nat Rev Cancer. 2012;12:298-306.

5. Zou W, Chen L. Inhibitory b7-family molecules in the tumour microenvironment. Nat Rev Immunol. 2008;8:467-77.

6. Iwai Y, Ishida M, Tanaka Y, Okazaki T, Honjo T, Minato N. Involvement of PD-L1 on tumor cells in the escape from host immune system and tumor immunotherapy by PD-L1 blockade. Proc Natl Acad Sci U S A. 2002;99:12293-7.

7. Gunturi A, Mc Dermott DF. Potential of new therapies like antipd1 in kidney cancer. Curr Treat Options in Oncol. 2014;15:13746.

8. Villaruz LC, Kalyan A, Zarour H, Socinski MA. Immunotherapy in lung cancer. Transl Lung Cancer Res. 2014;3:2-14.

9. Vousden $\mathrm{KH}, \mathrm{Lu} \mathrm{X}$. Live or let die: The cell's response to p53. Nature Reviews Cancer. 2002;2:594-604.

10. Travis WD, Brambilla E, Burke AP, Marx A, Nicholson AG. Introduction to The 2015 World Health Organization Classification of Tumors of the Lung, Pleura, Thymus, and Heart. J Thorac Oncol. 2015;10:1240-2.

11. Garon EB, Rizvi NA, Hui R, Leighl N, Balmanoukian AS, Eder JP, Patnaik A, Aggarwal C, Gubens M, Horn L, Carcereny E, Ahn MJ, Felip E, Lee JS, Hellmann MD, Hamid O, Goldman JW, Soria JC, Dolled-Filhart M, Rutledge RZ, Zhang J, Lunceford JK, Rangwala R, Lubiniecki GM, Roach C, Emancipator K, Gandhi L. Pembrolizumab for the treatment of non-small-cell lung cancer. N Engl J Med. 2015;372:2018-28.

12. Lotfi M, Afsharnezhad S, Raziee HR, Ghaffarzadegan K, Sharif S, Shamsara J, Lary S, Behravan J. Immunohistochemical assessment of MGMT expression and p53 mutation in glioblastoma multiforme. Tumori. 2011;97:104-8.

13. Donnem T, Hald SM, Paulsen EE, Richardsen E, Al-Saad S, Kilvaer TK, Brustugun OT, Helland A, Lund-Iversen M, Poehl M, Olsen KE, Ditzel HJ, Hansen O, Al-Shibli K, Kiselev Y, Sandanger TM, Andersen S, Pezzella F, Bremnes RM, Busund LT. Stromal CD8+ T-cell Density-A promising supplement to TNM staging in non-small cell lung cancer. Clin Cancer Res. 2015;21:2635-43.

14. Detterbeck FC, Boffa DJ, Tanoue LT. The new lung cancer staging system. Chest. 2009;136:260-71.

15. Keir ME, Liang SC, Guleria I, Latchman YE, Qipo A, Albacker LA, Koulmanda M, Freeman GJ, Sayegh MH, Sharpe AH. Tissue expression of PD-L1 mediates peripheral T cell tolerance. J Exp Med. 2006;203:883-95.

16. Hirahara K, Ghoreschi K, Yang XP, Takahashi H, Laurence A, Vahedi G, Sciumè G, Hall AO, Dupont CD, Francisco LM, Chen Q, Tanaka M, Kanno Y, Sun HW, Sharpe AH, Hunter CA, O'Shea JJ. Interleukin-27 priming of T cells controls IL-17 production in trans via induction of the ligand PD-L1. Immunity. 2012;36:101730 .

17. Mu CY, Huang JA, Chen Y, Chen C, Zhang XG. High expression of PD-L1 in lung cancer may contribute to poor prognosis and tumor cells immune escape through suppressing tumor infiltrating dendritic cells maturation. Med Oncol. 2011;28:682-8.
18. Wolfle SJ, Strebovsky J, Bartz H, Sähr A, Arnold C, Kaiser C, Dalpke AH, Heeg K. PD-L1 expression on tolerogenic APCs is controlled by STAT-3. Eur J Immunol. 2011;41:413-24.

19. Sundar R, Soong R, Cho B, Brahmer JR, Soo RA. Immunotherapy in the treatment of non small cell lung cancer. Lung Cancer. 2014;85:101-9.

20. Velcheti V, Schalper KA, Carvajal DE, Anagnostou VK, Syrigos KN, Sznol M, Herbst RS, Gettinger SN, Chen L, Rimm DL. Programmed death ligand-1 expression in non-small cell lung cancer. Lab Invest. 2014;94:107-16.

21. Boland JM, Kwon ED, Harrington SM, Wampfler JA, Tang H, Yang $\mathrm{P}$, Aubry MC. Tumor B7-H1 and B7-H3 expression in squamous cell carcinoma of the lung. Clin Lung Cancer. 2013;14:157-63.

22. Chen $\mathrm{Y}, \mathrm{Mu} \mathrm{C}$, Huang J. Clinical significance of programmed death-1 ligand-1 expression in patients with non-small cell lung cancer: A 5-year-follow-up study. Tumori. 2012;98:751-5.

23. Azuma K, Ota K, Kawahara A, Hattori S, Iwama E, Harada T, Matsumoto K, Takayama K, Takamori S, Kage M, Hoshino T, Nakanishi Y, Okamoto I. Association of PD-L1 overexpression with activating EGFR mutations in surgically resected non-small cell lung cancer. Ann Oncol. 2014;25:1935-40.

24. Konishi J, Yamazaki K, Azuma M, Kinoshita I, Dosaka-Akita H, Nishimura M. B7-H1 expression in non-small cell lung cancer cells and its relationship with tumor-infiltrating lymphocytes and their PD-1 expression. Clin Cancer Res. 2004;10:5094-100.

25. Yang CY, Lin MW, Chang YL, Wu CT4, Yang PC. Programmed cell death-ligand 1 expression in surgically resected stage I pulmonary adenocarcinoma and its correlation with driver mutations and clinical outcomes. Eur J Cancer. 2014;50:1361-9.

26. Schmidt LH, Kümmel A, Görlich D, Mohr M, Bröckling S, Mikesch JH, Grünewald I, Marra A, Schultheis AM, Wardelmann E, Müller-Tidow C, Spieker T, Schliemann C, Berdel WE, Wiewrodt R, Hartmann W. PD-1 and PDL1 expression in NSCLC indicate a favorable prognosis in defined subgroups. PLoS ONE. 2015;10:e0136023.

27. Schalper KA, Velcheti V, Carvajal D, Wimberly H, Brown J, Pusztai L, Rimm DL. In situ tumor PD-L1 mRNA expression is associated with increased TILs and better outcome in breast carcinomas. Clin Cancer Res. 2014;20:2773-82.

28. Droeser RA, Hirt C, Viehl CT, Frey DM, Nebiker C, Huber X, Zlobec I, Eppenberger-Castori S, Tzankov A, Rosso R, Zuber M, Muraro MG, Amicarella F, Cremonesi E, Heberer M, Iezzi G, Lugli A, Terracciano L, Sconocchia G, Oertli D, Spagnoli GC, Tornillo L. Clinical impact of programmed cell death ligand 1 expression in colorectal cancer. Eur J Cancer. 2013;49:2233-42.

29. Taube JM, Anders RA, Young GD, Xu H, Sharma R, McMiller TL, Chen S, Klein AP, Pardoll DM, Topalian SL, Chen L. Colocalization of inflammatory response with B7-h1 expression in human melanocytic lesions supports an adaptive resistance mechanism of immune escape. Sci Transl Med. 2012;4:127ra37.

30. Nowicki TS, Akiyama R, Huang RR, Shintaku IP, Wang X, Tumeh PC, Singh A, Chmielowski B, Denny C, Federman N, Ribas A. Infiltration of CD8 T cells and expression of PD-1 and PD-L1 in synovial sarcoma. Cancer Immunol Res. 2017;5:118-26. 
31. Chen C, Qu QX, Huang JA, Zhu YB, Ge Y, Wang Q, Zhang XG. Expression of programmed-death receptor ligands 1 and 2 may contribute to the poor stimulatory potential of murine immature dendritic cells. Immunobiology. 2007;212:159-65.

32. Khoury SJ, Sayegh MH. The roles of the new negative $\mathrm{T}$ cell costimulatory pathways in regulating autoimmunity. Immunity. 2004;20:529-38.
33. Ahrendt SA, Chow JT, Yang SC, Zhang MJ, Jen J, Sidransky D. Alcohol consumption and cigarette smoking increase the frequency of $\mathrm{p} 53$ mutations in non-small cell lung cancer. Cancer Res. 2000;60:3155-9.

34. Kan G, Dong W. The expression of PD-L1 APE1 and p53 in hepatocellular carcinoma and its relationship to clinical pathology. Eur Rev Med Pharmacol Sci. 2015;19:3063-71. 